\title{
Tuning the Surface Plasmon Resonance of Lanthanum Hexaboride to Absorb Solar Heat: A Review
}

\author{
Tracy M. Mattox *D and Jeffrey J. Urban * \\ Molecular Foundry, Lawrence Berkeley National Laboratory, Berkeley, CA 94720, USA \\ * Correspondence: tmmattox@lbl.gov (T.M.M.); jjurban@lbl.gov (J.J.U.); Tel.: +510-495-2649 (T.M.M.); \\ $+510-486-4526$ (J.J.U.)
}

Received: 5 November 2018; Accepted: 30 November 2018; Published: 5 December 2018

\begin{abstract}
While traditional noble metal $(\mathrm{Ag}, \mathrm{Au}$, and $\mathrm{Cu})$ nanoparticles are well known for their plasmonic properties, they typically only absorb in the ultraviolet and visible regions. The study of metal hexaborides, lanthanum hexaboride $\left(\mathrm{LaB}_{6}\right)$ in particular, expands the available absorbance range of these metals well into the near-infrared. As a result, $\mathrm{LaB}_{6}$ has become a material of interest for its energy and heat absorption properties, most notably to those trying to absorb solar heat. Given the growing popularity of $\mathrm{LaB}_{6}$, this review focuses on the advances made in the past decade with respect to controlling the plasmonic properties of $\mathrm{LaB}_{6}$ nanoparticles. This review discusses the fundamental structure of $\mathrm{LaB}_{6}$ and explains how decreasing the nanoparticle size changes the atomic vibrations on the surface and thus the plasmonic absorbance band. We explain how doping $\mathrm{LaB}_{6}$ nanoparticles with lanthanide metals $(\mathrm{Y}, \mathrm{Sm}$, and $\mathrm{Eu}$ ) red-shifts the absorbance band and describe research focusing on the correlation between size dependent and morphological effects on the surface plasmon resonance. This work also describes successes that have been made in dispersing $\mathrm{LaB}_{6}$ nanoparticles for various optical applications, highlighting the most difficult challenges encountered in this field of study.
\end{abstract}

Keywords: lanthanum hexaboride; $\mathrm{LaB}_{6}$; plasmon; nanoparticles; heat absorption

\section{Introduction}

Traditional plasmonic metals $(\mathrm{Ag}, \mathrm{Au}$, and $\mathrm{Cu})$ possess enormous free carrier densities, and when confined on the nanoscale the quantized free electron oscillations result in sharp localized surface plasmon resonance (LSPR) modes. The LSPR properties enhance light-matter interactions, making these materials ideal for a wide variety of electronic and optical applications [1-4]. Furthermore, their sensitivity to small changes within their structure (e.g., size, morphology, atomic vacancies, etc.) makes the properties easy to tune by introducing defects or changing the surface by varying the size or shape.

The ability of plasmonic metals to convert solar light into electricity and chemical energy is well documented, but the absorbance is restricted to the ultraviolet and visible spectrums in traditional plasmonic metals (Figure 1). This leaves the near infrared (NIR) region mostly inaccessible to metal nanoparticles, with the exception of novel engineered geometries of some metals, such as the cases of Au nanowires and shells $[5,6]$. There is a growing need to find materials with a NIR absorbance for applications such as window coatings to absorb solar heat $[7,8]$. Researchers attempting to reduce heat entering buildings and automobiles through windows need a visibly transparent material that absorbs the most intense radiative heat from the sun, ideally in the range of 750-1200 nm. While some chalcogenides and metal oxides are potential candidates [9-14], the metal borides are often overlooked. 


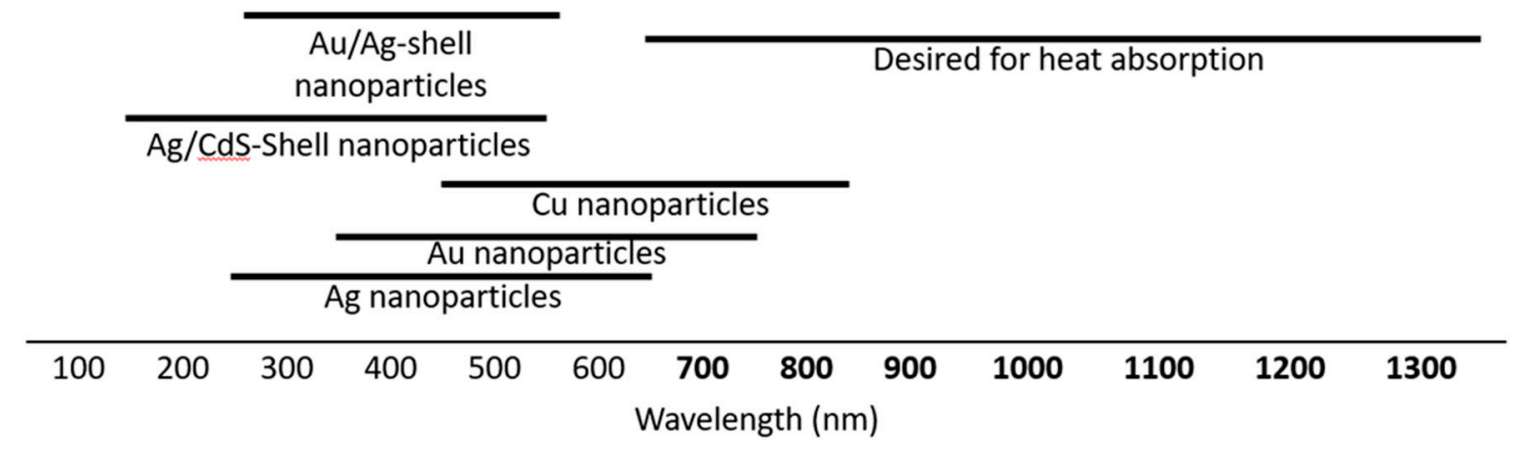

Figure 1. Typical absorbance range of plasmonic metal nanoparticles: Ag [15], Au [16], Cu [17], Ag/CdS-shell [18], Au/Ag-shell [19], and the desired range to absorb solar heat.

Lanthanum hexaboride $\left(\mathrm{LaB}_{6}\right)$ is a plasmonic metal with a large free carrier density [20-22] that is best known for its impressive thermionic emission properties and low work function [23-29]. However, $\mathrm{LaB}_{6}$ also absorbs light very strongly at about $1000 \mathrm{~nm}$, which falls well within the targeted range to absorb solar heat $[30,31]$. The optical properties of $\mathrm{LaB}_{6}$ nanoparticles coupled with its incredible hardness [32-36] and high thermal stability [37-43] make it an excellent choice to include in alloys and composites for solar window applications.

The ability to directly synthesize $\mathrm{LaB}_{6}$ on the nanoscale has only recently become a reality, so research focusing on plasmonic control in $\mathrm{LaB}_{6}$ is relatively new. That said, $\mathrm{LaB}_{6}$ does offer the same wide range of methods for optical tuning as other LSPR particles, including controlling the carrier density through vacancies and doping, particle size, morphology, and the surrounding media (i.e. ligands and polymer matrices) [10,44-47]. There is still much to be learned about the optical properties of $\mathrm{LaB}_{6}$ nanoparticles, but what has been discovered thus far has been quite exciting and has made $\mathrm{LaB}_{6}$ a very popular material of interest in recent years.

This review focuses on the advances that have been made in the last decade with respect to tuning the plasmon of $\mathrm{LaB}_{6}$ nanoparticles. Though this field is still relatively new, we feel that the growing demand for optically tunable $\mathrm{LaB}_{6}$ warrants a comprehensive review to explain the nuances of controlling the plasmon of $\mathrm{LaB}_{6}$. This work describes how some of the fundamentals behind this intriguing material correspond with the optical properties, and how doping, size, and morphology are contributing factors when attempting to meet requirements of desired plasmonic applications.

\section{Relating $\mathrm{LaB}_{6}$ Fundamentals to Plasmonics}

\subsection{Crystal Structure of $\mathrm{LaB}_{6}$}

$\mathrm{LaB}_{6}$ is composed of interconnecting hexaboride clusters with lanthanum (La) atoms residing in the interstitial spaces (Figure 2A) [48]. It is well known that the boron network is responsible for the rigidity of the structure, and consequently the thermal and mechanical stability. Though $\mathrm{La}$ is not bound within the system it does provide electrons to stabilize the structure. Interestingly, this rigid material is more relaxed on the particle surface (Figure 2B) [49-51]. On the outermost surface, lanthanum atoms relax closer to the $B_{6}$ framework while the $B_{6}$ octahedral clusters relax and expand slightly outwards. Though this relaxation is insignificant to the optical properties of bulk sized $\mathrm{LaB}_{6}$, the surface vibrations of nanoparticles are incredibly important when attempting to control the LSPR.

Researchers are still exploring the surface chemistry of $\mathrm{LaB}_{6}$, and remain uncertain of the mechanistic details of crystal formation and growth. Until recently, it was assumed that high temperatures $\left(>1500{ }^{\circ} \mathrm{C}\right)$ were required to make $\mathrm{LaB}_{6}$, most often by reacting lanthanum salt (e.g., $\left.\mathrm{LaCl}_{3}\right)$ with sodium borohydride $\left(\mathrm{NaBH}_{4}\right)$. Unfortunately, the quick nucleation and growth at such high temperatures prevents the direct synthesis of nano-sized $\mathrm{LaB}_{6}$. In typical nanoparticle syntheses, it is important to control the rate of nucleation and growth in order to make particles of a uniform size. This is often accomplished by varying temperature, concentration, or including additives 
(ligands) [52,53]. Unfortunately, the assumed high temperature requirements make small adjustments traditionally used in nanoparticle work impossible, especially the incorporation of organic ligands that cannot withstand the extreme heat. As a result, researchers have had to rely on ball milling techniques to reduce the size of $\mathrm{LaB}_{6}$, which introduces contaminants by the very nature of the process [54-56]. In recent years, researchers have found that significantly lowering the heat can yield phase-pure $\mathrm{LaB}_{6}$ nanoparticles using a variety of methods, including tube furnaces $[57,58]$, autoclaves $[59,60]$, and vapor deposition [61,62]. In reducing the reaction temperature, the nucleation and growth rate is significantly reduced, making it possible to observe crystal lattice formation through in-situ diffraction measurements [48]. Researchers have recently discovered that in low temperature reactions the halogen on the lanthanum salt acts as a bridging ligand between La atoms $[48,58,63]$. When these LaB 6 nanoparticles are heated, the halogen atoms force the lattice to contract until the halogen is removed (Figure 2C). This has important implications to LSPR studies, which are incredibly sensitive to the particle surface.

A

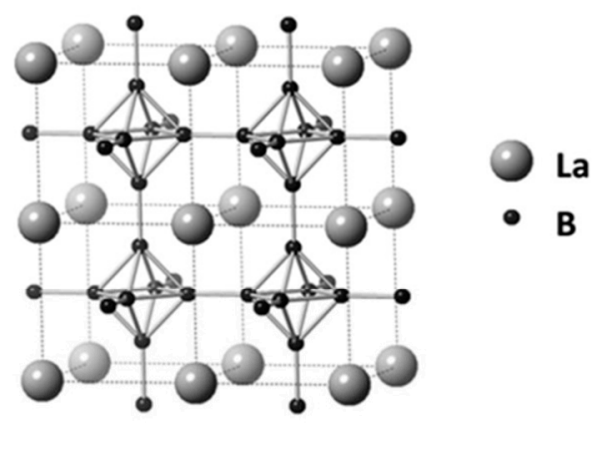

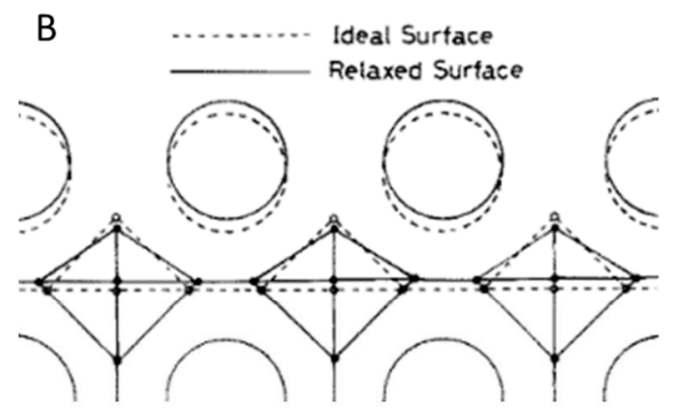

C
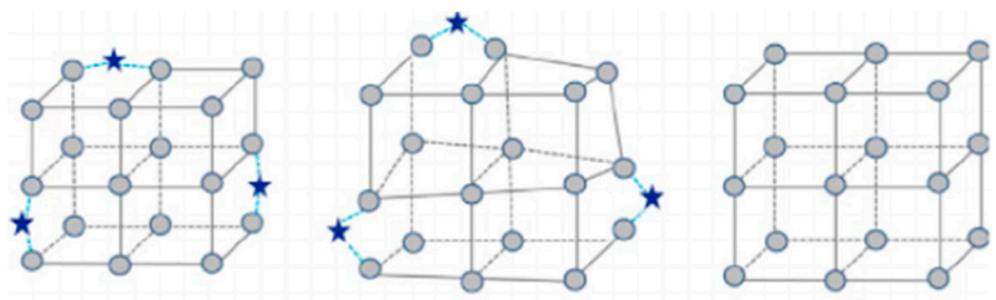

\section{Increased Heating of Nanoparticles}

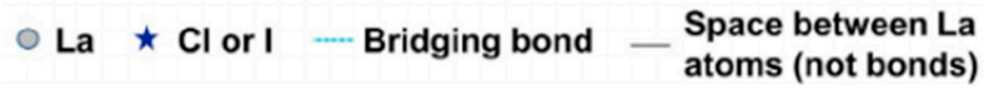

Figure 2. (A) Four unit cells of lanthanum hexaboride $\left(\mathrm{LaB}_{6}\right)$ with a lattice constant of approximately $4.15 \AA$ (reprinted from [48]). (B) Position of La (circle) and $\mathrm{B}_{6}$ (diamond) in relaxed and ideal states on $\mathrm{LaB}_{6}$ surface (reprinted from [49]). (C) Removal of halogen bridge between La atoms with continued heating of $\mathrm{LaB}_{6}$ nanoparticle (reprinted from [58]).

\subsubsection{Vibrational Structure of $\mathrm{LaB}_{6}$}

Decreasing the particle size of $\mathrm{LaB}_{6}$ increases the surface area, and in the case of extremely small sizes it becomes possible for the nanoparticles to be composed almost entirely of surface atoms. As a result, minor changes to the surface composition can have a significant impact on the lattice and consequently the LSPR. In order to use this concept to fine tune the position of the plasmon, it is essential to first describe the vibrational modes of $\mathrm{LaB}_{6}$, which are displayed in Equation (1).

$$
\Gamma=A_{1 g}+E_{g}+T_{1 g}+T_{2 g}+3 T_{1 u}+T_{2 u}
$$

As seen in Figure $3 \mathrm{~A}$, the vibrational modes of the $\mathrm{B}_{6}$ cluster in $\mathrm{LaB}_{6}$ include the bending $\left(\mathrm{T}_{2 \mathrm{~g}}\right)$ and stretching $\left(E_{g}\right.$ and $\left.A_{1 g}\right)$ modes, while La includes vibrations from moving within the boron cage 
("rattling mode") and movement with respect to the boron cage $\left(\mathrm{T}_{1 \mathrm{u}}\right)$. When $\mathrm{LaB}_{6}$ particles decrease in size from bulk to $2.5 \mathrm{~nm}$, there is a shift to higher energy for all of the $\mathrm{B}_{6}$ cluster vibrational modes due to the increased surface area which has a larger number of relaxed $\mathrm{B}_{6}$ on the surface (Figure $3 \mathrm{~B}$ ). Furthermore, different sized halogens from the La salt precursor also impact the vibration modes, where larger atoms take up more space as bridging atoms that increase the vibrational energy. More details on the direct influence of particle size on the plasmon position will be discussed below.

A
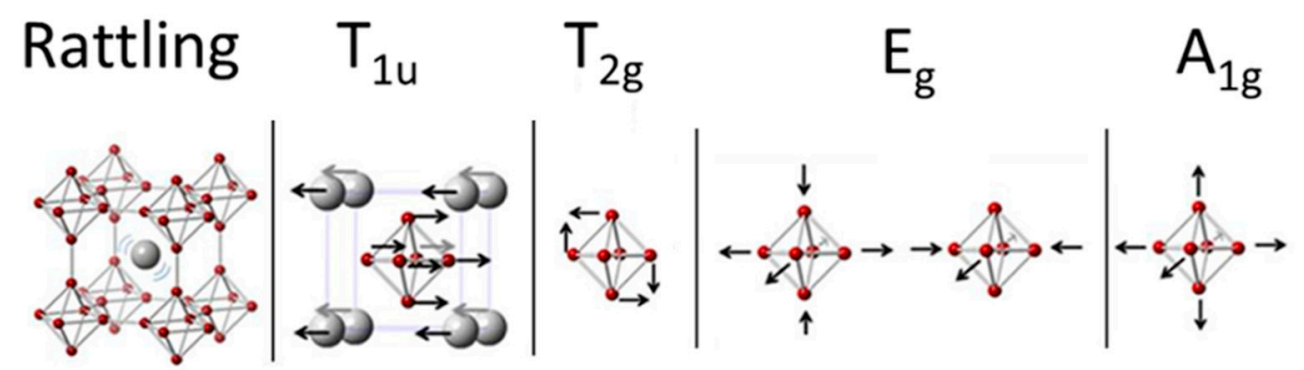

B

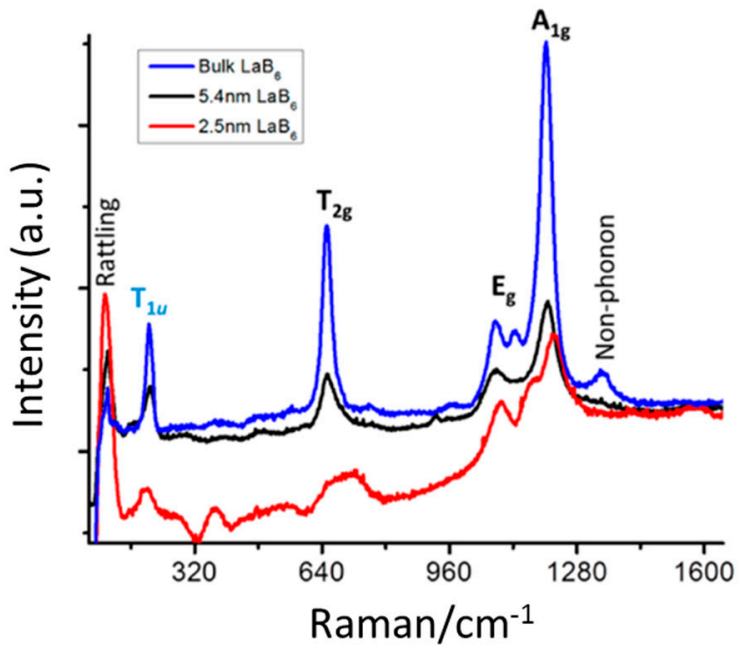

C

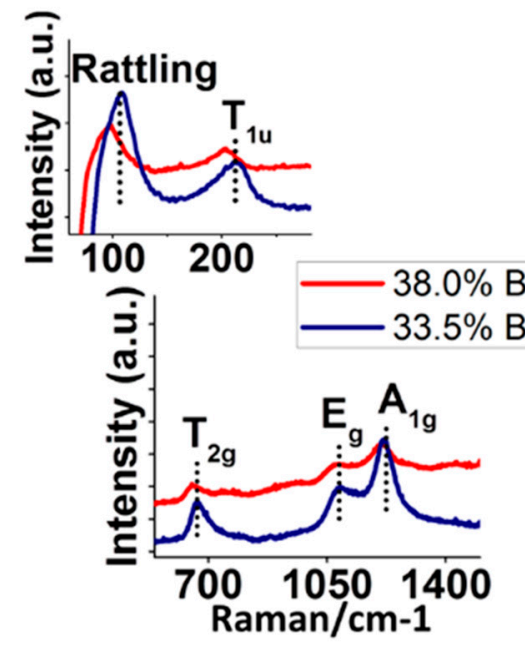

Figure 3. (A) Raman active vibrational modes of $\mathrm{LaB}_{6}$; (B) vibrational mode changes with changing nanoparticle sizes; and $(\mathbf{C})$ shifting vibrational modes of $6.2 \mathrm{~nm}$ particles with varying $\mathrm{B}$ content (reprinted from [63]).

\subsubsection{Structural Defects}

$\mathrm{LaB}_{6}$ is well known to have defects within the structure, and is often non-stoichiometric because La atoms are missing or excess boron is residing in the interstitial spaces. As with other plasmonic systems, these defects can be advantageous to scientists when tuning the optical properties so long as the defects can be predicted and controlled. Only recently have researchers published on the ability to control La defects simply through reaction temperature and heating rate [64]. When the system is not stoichiometric (6B:1La) and the $\% \mathrm{~B}$ is increased (La atoms are missing) the Raman vibrations shift to lower energy. This is very clear in Figure 3C when comparing $6.2 \mathrm{~nm}$ particles containing $38.0 \%$ and $33.5 \% \mathrm{~B}$ (note that stoichiometric $\mathrm{LaB}_{6}$ contains $31.8 \% \mathrm{~B}$ ). The vacant lanthanum positions of the structure lower the overall energy of the system, and with less La available there are fewer electrons contributing to the structure, which causes the plasmon to shift. 


\section{Controlling the Plasmon of $\mathrm{LaB}_{6}$}

The structure of $\mathrm{LaB}_{6}$ is exceptionally robust. Although vacancies and slight changes to the crystal structure clearly influence the position of the plasmon, it is possible to move beyond the fundamental structure to find other knobs to control the plasmonic properties. Similar to chalcogenides and metal oxides, $\mathrm{LaB}_{6}$ is significantly influenced by the particle size and the shape of the surface. Unlike traditional noble-metal based materials, $\mathrm{LaB}_{6}$ has the ability to incorporate dopants within its structure, which offers an additional means to increase the free carrier density and red-shift the frequency of the plasmon.

\subsection{Doping}

$\mathrm{LaB}_{6}$ is well known for its stability, even when La vacancies leave unfilled holes within the crystal lattice. Like all boron frameworks, the $\mathrm{B}_{6}$ network is electron-deficient and stable only as a result of electron transfer from the surrounding metals [65]. The natural defects or holes found in the $\mathrm{LaB}_{6}$ framework make this material ideal for incorporating other metals via doping to tune the optical properties. However, few people have been successful in producing phase-pure hexaboride nanoparticles containing more than one type of metal, and fewer still have considered plasmonic changes in these doped systems. Fortunately, the introduction of dopants into $\mathrm{LaB}_{6}$ offers a promising route to plasmon control.

Part of the difficulty arises from the nature of the synthesis. The mechanism of formation is not understood, and it is only in very recent years that researchers have found ways to control nucleation and growth in $\mathrm{LaB}_{6}$ by significantly reducing the reaction temperature. The other difficulty in doping $\mathrm{LaB}_{6}$ is that the metal does not form a direct bond with the rigid $\mathrm{B}_{6}$ framework. As a result, $\mathrm{LaB}_{6}$ is not influenced much by differing sizes of metal atoms that could alter the structure and shift the plasmon. The contribution of electrons from the metal to the structure also means that attempting to dope the trivalent $\mathrm{La}^{3+}$ containing $\mathrm{LaB}_{6}$ with other trivalent metals will not shift the plasmon because the free electron density will not change [66]. Consequently, researchers must be very selective when designing doped $\mathrm{LaB}_{6}$ nanoparticles when intending to tune the plasmon. Doping this system also changes the vacancies within the crystal lattice, so careful attention must be paid to determine whether the dopants or vacancies are responsible for changes to the optical properties.

Studies of the Fermi level may help provide insight into the movement of electrons within the system. The spatial distribution of electrons near the Fermi level was recently reported for trivalent $\mathrm{LaB}_{6}$ and divalent $\mathrm{BaB}_{6}[67]$, and weak electron lobes were found around the interior- $\mathrm{B}_{6}$ octahedral bond (Figure 4A). Comparing theoretical and experimental work, it was determined that these electron lobes were responsible for the conductive $\pi$-electrons in $\mathrm{LaB}_{6}$. Trivalent $\mathrm{LaB}_{6}$ behaves as a metal while divalent hexaborides (i.e. $\mathrm{BaB}_{6}$ ) are semiconductors [68], but how do these and the optical properties change when $\mathrm{LaB}_{6}$ becomes a mixed valence system? Below are the few examples in the literature that tune the plasmon of $\mathrm{LaB}_{6}$ nanoparticles by doping the material with divalent lanthanide metals, including some comments on how the changed Fermi surface influences the LSPR. In all cases, introducing a lanthanide metal as a dopant in the system causes a red-shift of the plasmon. 
A

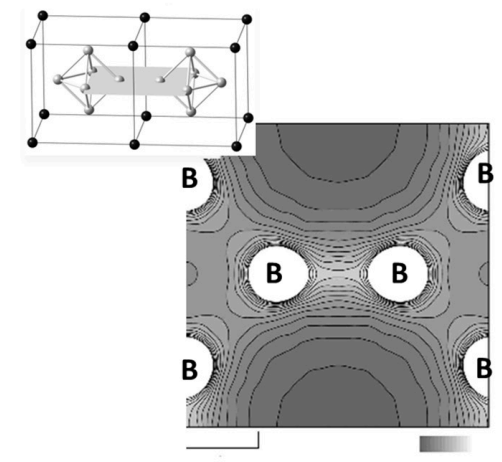

$\mathrm{C}$

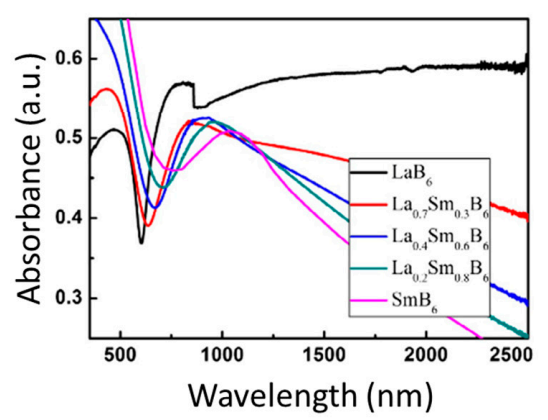

B

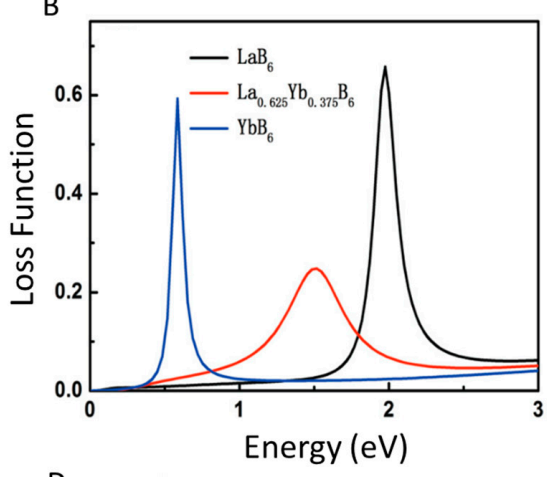

D

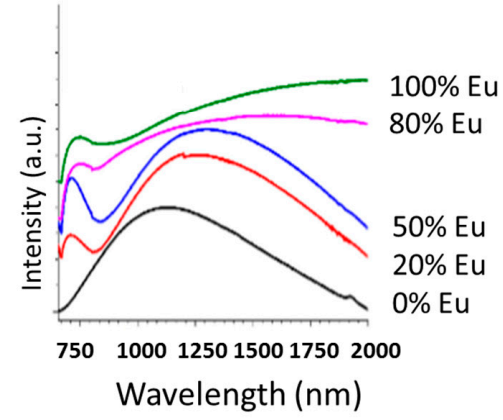

Figure 4. (A) Total charge density map of $\mathrm{LaB}_{6}$ (grey scale shows increasing charge density) (reprinted from [67]). (B) Energy loss function of $\mathrm{LaB}_{6}, \mathrm{La}_{0.625} \mathrm{Yb}_{0.375} \mathrm{~B}_{6}$ and $\mathrm{YbB}_{6}$ in the low energy region (reprinted from [69]). (C) Absorbance spectra of $\mathrm{SmB}_{6}, \mathrm{La}_{0.2} \mathrm{Sm}_{0.8} \mathrm{~B}_{6}, \mathrm{La}_{0.4} \mathrm{Sm}_{0.6} \mathrm{~B}_{6}, \mathrm{La}_{0.7} \mathrm{Sm}_{0.3} \mathrm{~B}_{6}$ and $\mathrm{LaB}_{6}$ (reprinted from [70]). (D) Absorbance spectra of $\mathrm{La}_{x} \mathrm{Eu}_{1-\mathrm{x}} \mathrm{B}_{6}$ changing with Eu concentration (normalized) (reprinted from [71]).

\subsubsection{Yb-Doped $\mathrm{LaB}_{6}$ Nanoparticles: Theory}

A recent report used density functional theory (DFT) first-principal calculations to study the potential optical effects of $\mathrm{LaB}_{6}$ nanoparticles doped with ytterbium $(\mathrm{Yb})$, and found that the $4 \mathrm{f}$ states of the $\mathrm{Yb}$ dopant at the Fermi surface have the potential to uniquely influence the optical properties, due to the participation of f-orbitals [69]. This is clear in Figure 4B, which compares phase pure $\mathrm{YbB}_{6}, \mathrm{LaB}_{6}$, and $\mathrm{La}_{0.625} \mathrm{Yb}_{0.375} \mathrm{~B}_{6}$ in the energy loss spectra (another method for measuring plasmon energies). Doping $\mathrm{LaB}_{6}$ with $\mathrm{Yb}$ is expected to reduce the plasmon energy of the system, coinciding with a change of the LSPR. The concentration of charge carriers in the system decreases and reduces the plasma frequency when some of the La atoms are replace with $\mathrm{Yb}$, which causing the minimum plasma absorption to shift to higher wavelengths. Though the calculations suggest that $\mathrm{Yb}$-doping $\mathrm{LaB}_{6}$ should indeed tune the plasmon, such an experiment has yet to be reported.

\subsubsection{Sm-Doped $\mathrm{LaB}_{6}$ Nanoparticles}

The first synthetic example of $\mathrm{LaB}_{6}$ nanoparticles doped with a trivalent metal was reported using samarium (Sm) [70]. With the aid of DFT calculations, it was determined that the shift of the optical properties was due to the changing $\mathrm{Sm} 4 \mathrm{f}$ states near the Fermi surface of $\mathrm{LaB}_{6}$ after doping. The same as was predicted for $\mathrm{Yb}$ doping, with a reduced number of conduction electrons causing the shift of absorption spectra. When increasing the Sm content in $\mathrm{SmB}_{6}$ the plasmon peak shifts to higher wavelengths, which is clear as the onset of the absorbance peak shifts from $603 \mathrm{~nm}$ for $\mathrm{LaB}_{6}$ to $756 \mathrm{~nm}$ for $\mathrm{SmB}_{6}$ (Figure 4C).

\subsubsection{Eu-Doped $\mathrm{LaB}_{6}$ Nanoparticles}

A low temperature solid-state synthesis was employed to dope $\mathrm{LaB}_{6}$ with europium $(\mathrm{Eu})$, forming a single phase of $\mathrm{La}_{x} \mathrm{Eu}_{1-x} \mathrm{~B}_{6}$ nanoparticles [71]. Combining divalent $\mathrm{Eu}^{2+}$ and trivalent $\mathrm{La}^{3+}$ changed 
the free electron density of the system, resulting in a shift of the plasmon when changing the ratios of the two metals (Figure 4D). Increasing the concentration of $\mathrm{Eu}^{2+}$ significantly increased the number of metal vacancies in the structure, which allowed the plasmon to be tuned across a very wide range (1100 $\mathrm{nm}$ to $2050 \mathrm{~nm})$.

\subsection{Nanoparticle Size}

In addition to doping, controlling the size of phase-pure $\mathrm{LaB}_{6}$ also offers a means of control when tuning the position of the plasmon, where shifts of size and shape change the particle surface enough to influence the resonant frequency [72]. However, due to past difficulties in synthesizing $\mathrm{LaB}_{6}$ nanoparticles directly, it has been difficult to directly synthesize a series of pure $\mathrm{LaB}_{6}$ with varying nanoparticle sizes.

Theoretical models using DFT clearly show how particle sizes ranging from $10 \mathrm{~nm}$ to $100 \mathrm{~nm}$ can shift the LSPR, where the larger the particle the longer the wavelength absorbed so long as the particles are smaller than $80 \mathrm{~nm}$ (Figure 5A) [73]. In contrast, $\mathrm{LaB}_{6}$ nanoparticles larger than $80 \mathrm{~nm}$ are too big to influence the plasmon and have a lower efficiency for NIR absorbance. Experiments of particles below $5 \mathrm{~nm}$ have shown that even a small difference in size has a notable impact on the position of the plasmon. For example, increasing the particle size of phase pure $\mathrm{LaB}_{6}$ from $2.1 \mathrm{~nm}$ to 4.7 nm red-shifts the absorbance from $1080 \mathrm{~nm}$ to $1250 \mathrm{~nm}$, and the same red shift trend is observed when a diol-based ligand is included, where changing the size from $2.5 \mathrm{~nm}$ to $2.8 \mathrm{~nm}$ moves the plasmon from $1190 \mathrm{~nm}$ to $1220 \mathrm{~nm}$ (Figure 5B) [74]. Interestingly, with particles well below $10 \mathrm{~nm}$ in size the DFT calculations predicting the position of the plasmon are lower than the actual values, and further work is needed to understand what additional contributions from such small sized particles influence the LSPR theoretical calculations.
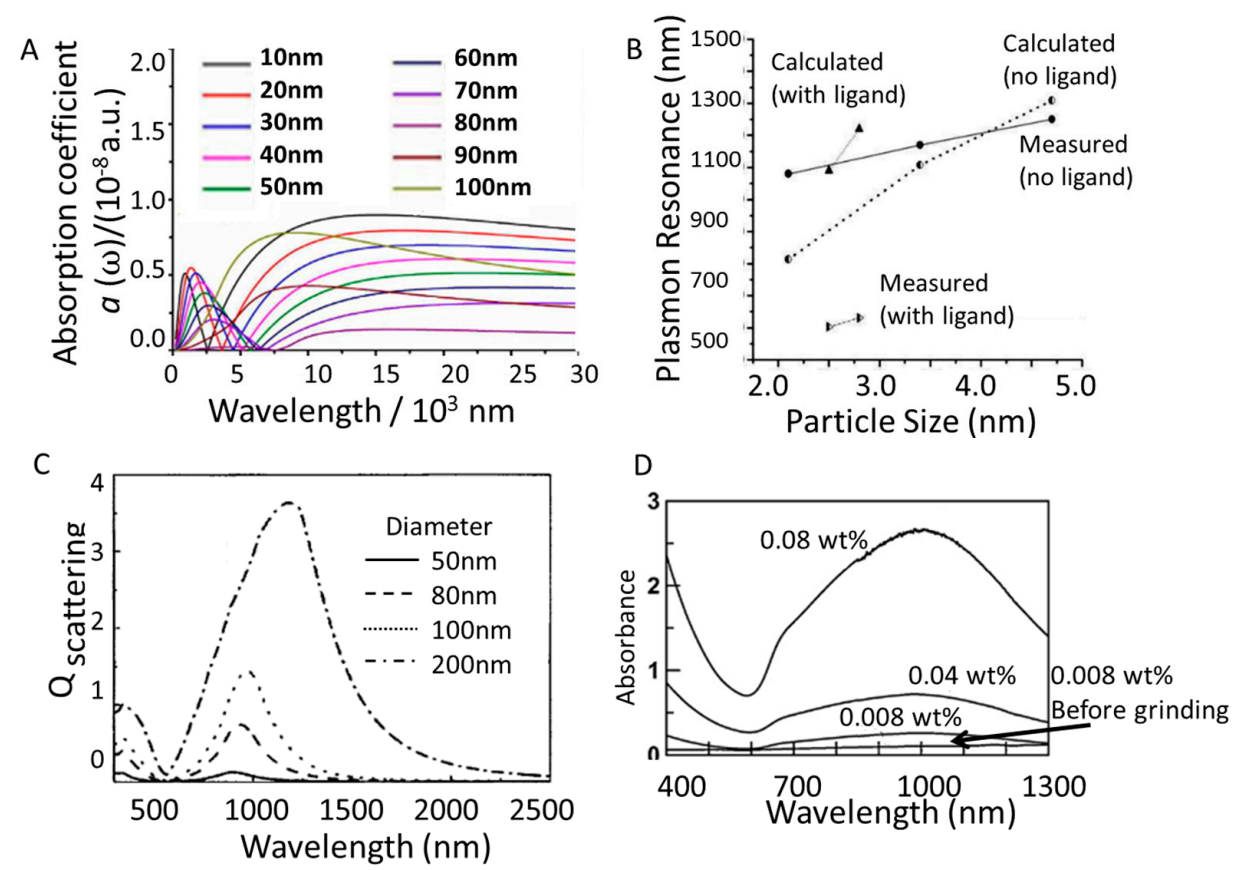

Figure 5. (A) Modeled absorption spectrum for $\mathrm{LaB}_{6}$ nanoparticles ranging from $10 \mathrm{~nm}$ to $100 \mathrm{~nm}$ (reprinted from [73]). (B) Calculated and measured (via diffuse reflectance) LSPR peak positions of ligand-free and ligand-bound $\mathrm{LaB}_{6}$ nanoparticles (reprinted from [74]). (C) Calculated scattering efficiency of single spherical $\mathrm{LaB}_{6}$ nanoparticles embedded in a polymer for sizes ranging from $50 \mathrm{~nm}$ to $200 \mathrm{~nm}$ (inset shows fraction of scattering to total extinction efficiency at $500 \mathrm{~nm}$ ) (reprinted from [30]). (D) Absorption spectra for ethylene glycol dispersion of $\mathrm{LaB}_{6}$ powders before and after grinding at different concentrations (reprinted from [75]). 
Calculations have also found that the scattering efficiency changes when adding different sizes of $\mathrm{LaB}_{6}$ to a polymer matrix (Figure $5 \mathrm{C}$ ), which ought to be considered when developing films for window coatings. Decreasing the nanoparticle size from $200 \mathrm{~nm}$ to $50 \mathrm{~nm}$ significantly red-shifts the plasmon, and not only increases the intensity of the scattering but broadens the scatter as well. It should also be noted that the shape of the scattering coefficient curve changes in particles larger than $80 \mathrm{~nm}$, which may be indicative of size-dependent LSPR behavior. When attempting to design a material that will capture a wide wavelength range, like the solar heat from $750 \mathrm{~nm}$ to $1200 \mathrm{~nm}$ mentioned above, it is ideal to use nanomaterials with a broad and intense absorbance peak [30].

Bulk sized $\mathrm{LaB}_{6}$ may also be reduced in size through grinding in the presence of a surfactant such as dodecylbenzene-sulfonic acid (DBS). The DBS makes it easier to disperse $100 \mathrm{~nm}$ particles into ethylene glycol, with the absorbance intensity increasing in higher particle concentrations (Figure 5D) [75]. This makes $\mathrm{LaB}_{6}$ a feasible NIR photothermal conversion material.

\subsection{Morphology}

In addition to size, the plasmonics of nanoparticles can also be tuned by altering the morphology of the system, where introducing different facets has a large impact on how free electrons behave on the surface [76]. Unfortunately, publications describing more than one nanoparticle shape of $\mathrm{LaB}_{6}$ are uncommon due to synthetic limitations, and those connecting shape and LSPR are even more rare. Whether morphological limitations are due to the chemistry itself or if low temperature methods simply need additional time to study has yet to be determined. The shape of $\mathrm{LaB}_{6}$ nanoparticles tends to be described as generic nanoparticles (assumed spheres) versus cubes [56,77] (Figure 6A) or as nanowires [78-80], but to our knowledge only two publications to date tie plasmonics to varying particle shape [81,82].

A
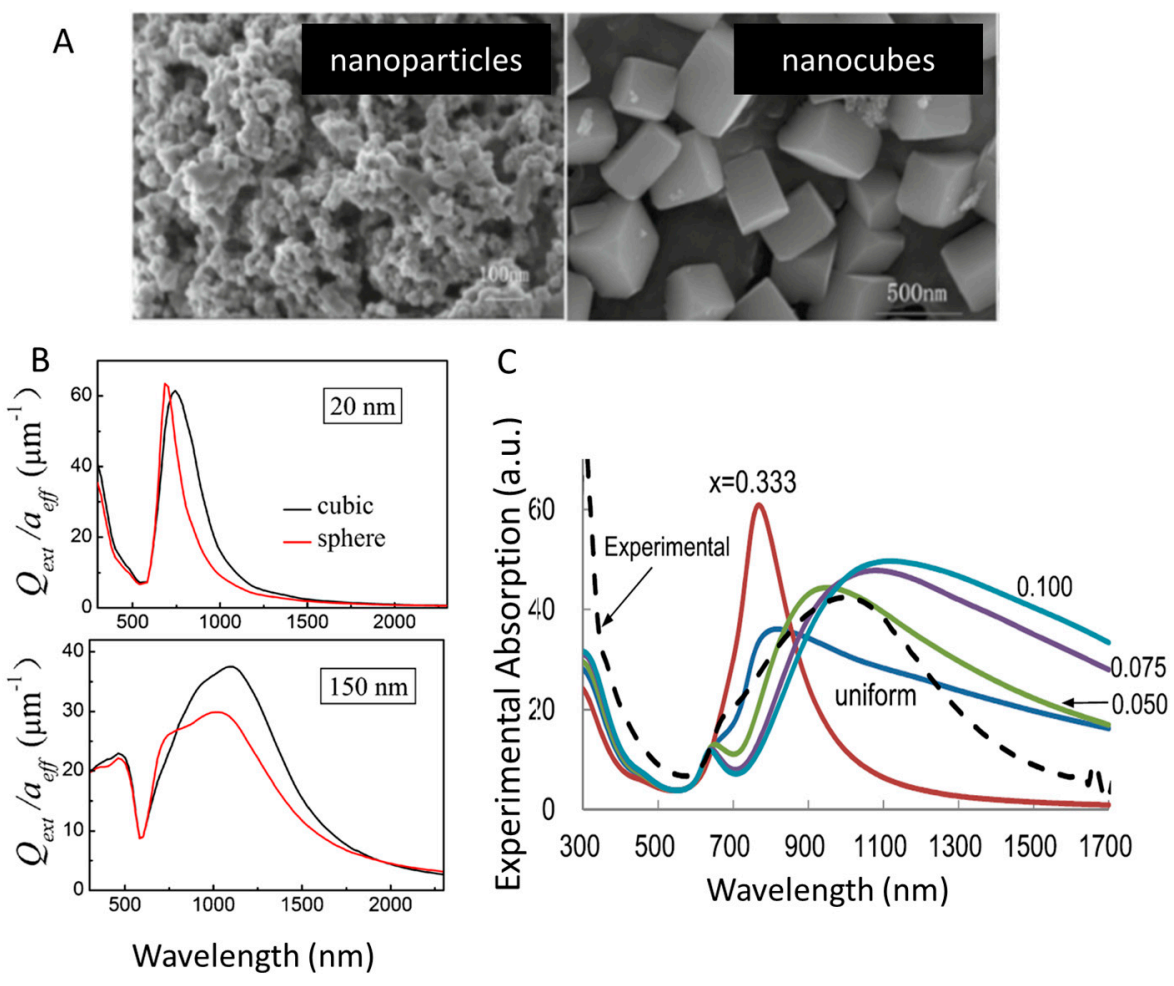

Figure 6. (A) SEM images of $\mathrm{LaB}_{6}$ nanoparticles and nanocubes (reprinted from [57]). (B) Comparison of extinction efficiencies divided by effective radius between cubic and spherical $\mathrm{LaB}_{6}$ particles (reprinted from [82]). (C) Absorption cross sections calculated for 100,000 $\mathrm{LaB}_{6}$ oblate particles with different aspect ratios and a standard deviation of 0.1 (reprinted from [81]). 
The optical response of $\mathrm{LaB}_{6}$ nanoparticles of varying sizes and shapes was compared using the discrete dipole approximation and experimental results were in agreement with the findings [82]. Comparing the extinction efficiencies of cubic and spherical particles of the same diameter (Figure 6B), it is clear that the optical properties are significantly influenced by the shape of the particles and that the nanocubes exhibit stronger NIR extinction. The Mie integration method is also an effective means of estimating optical properties of nanoparticles of changing sizes and shapes [83]. For $\mathrm{LaB}_{6}$, it was found that increasing the aspect ratio of spheroids can enhance the LSPR properties in the NIR [81]. In oblate spheroids, decreasing the aspect ratio has the effect of red-shifting the LSPR, and can significantly broaden the absorbance peak (Figure 6C).

\section{Improving $\mathrm{LaB}_{6}$ Plasmonic Applications}

In order to make $\mathrm{LaB}_{6}$ nanoparticles feasible as coatings for various solar energy and window applications, researchers must gain an understanding of plasmonic behaviors when incorporating the particles into films. Once the surrounding media is changed, the absorbance and intensity of the LSPR signal is also altered. To make cleaner films, $\mathrm{LaB}_{6}$ nanoparticles can be put into solutions using various polymer matrixes $[84,85]$. As with the changing particle concentrations mentioned above, varying the size of $\mathrm{LaB}_{6}$ nanoparticles (while maintaining the same concentration) in polymethyl methacrylate (PMMA) composites changes the absorbance intensity (Figure 7A), and the ideal particle size to achieve maximum intensity is just below $100 \mathrm{~nm}$ [86]. A similar effect has been observed in the transmittance and reflectance profiles of $\mathrm{LaB}_{6}$ nanoparticles dispersed in acrylic coatings, where decreasing the $\mathrm{LaB}_{6}$ concentration increases the transmittance intensity (Figure 7B) [87].
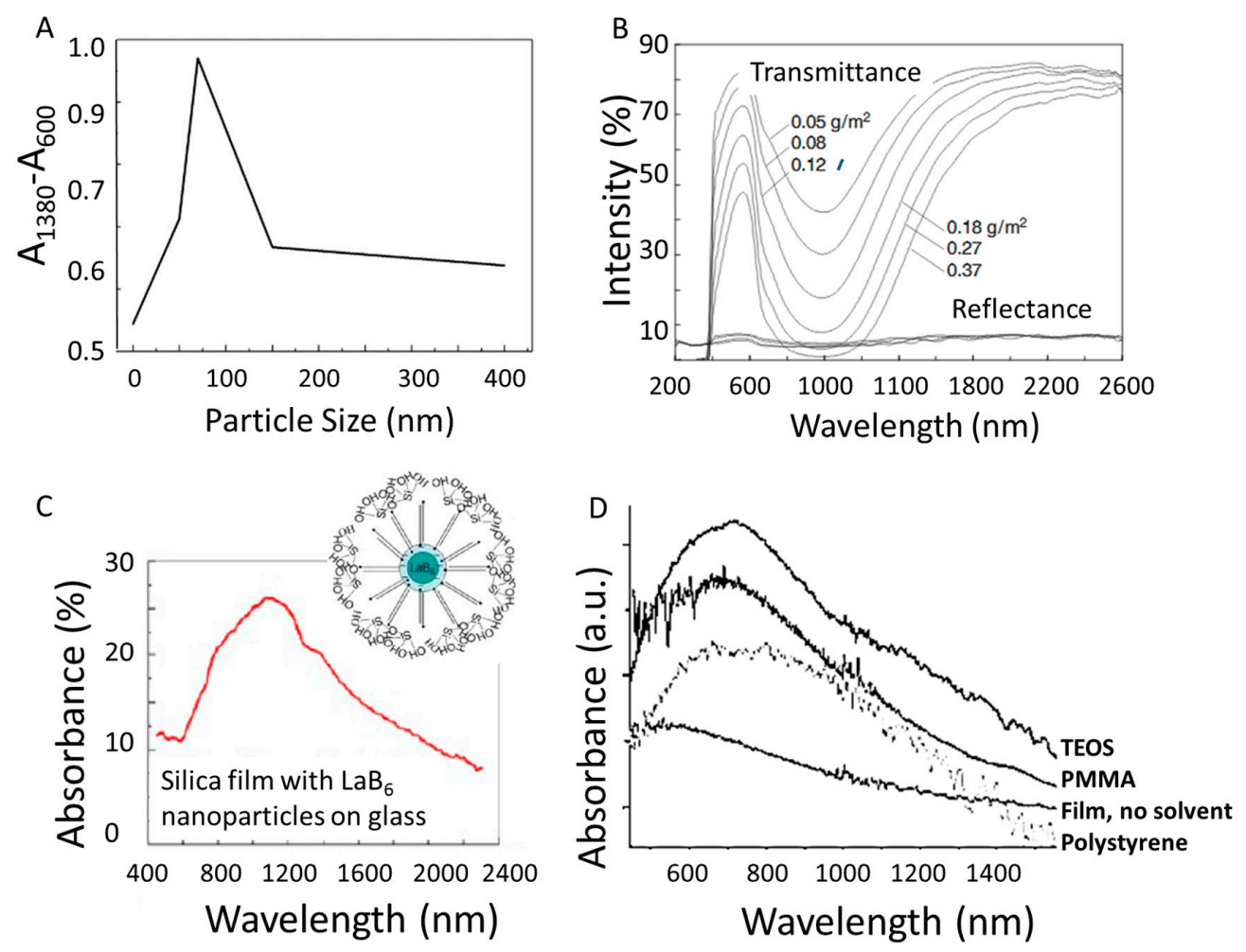

Figure 7. (A) Relative strength of absorption in composites containing $\mathrm{LaB}_{6}$ particles of different sizes; $0 \mathrm{~nm}$ represents pure polymer without $\mathrm{LaB}_{6}$. (reprinted from [86]). (B) Transmittance and reflectance profiles of $\mathrm{LaB}_{6}$ nanoparticle-dispersed acrylic coatings with different thicknesses on PET films (reprinted from [87]). (C) Absorbance spectra of cetyltrimethyl ammonium bromide (CTAB)-stabilized $\mathrm{LaB}_{6}$ nanoparticles (reprinted from [84]). (D) Absorbance spectra of 2.8nm ligand-bound $\mathrm{LaB}_{6}$ nanoparticles embedded in polymethyl methacrylate (PMMA), polystyrene, and tetraethoxyorthosilane (TEOS)-derived glass (reprinted from [74]). 
Creating visibly clear films with $\mathrm{LaB}_{6}$ remains an ongoing challenge. Since $\mathrm{LaB}_{6}$ nanoparticles are typically made with no ligands, they tend to aggregate with no physical barrier keeping them apart. To improve upon this, researchers are starting to develop methods to incorporate surfactants directly on the surface of $\mathrm{LaB}_{6}$. For example, using cetyltrimethyl ammonium bromide (CTAB) as a surfactant coating makes it possible to stabilize and reduce the agglomeration of $\mathrm{LaB}_{6}$ nanoparticles in water (Figure $7 \mathrm{C}$ ). There has also been a report of incorporating a ligand during the $\mathrm{LaB}_{6}$ reaction using a low temperature method to convert isophthalic acid to 1,3-phenylenedimethanol in-situ, with the diol binding to the $\mathrm{LaB}_{6}$ surface as soon as it is formed in-situ [74]. As a result, the ligand-bound $\mathrm{LaB}_{6}$ nanoparticles can be embedded directly into various polymer matrixes without the need for additional treatment, producing unaggregated and clear films composed of $\mathrm{LaB}_{6}$ in PMMA, polystyrene, or tetraethoxyorthosilane (TEOS) glass (Figure 7D). While this review focuses on tuning the plasmon of $\mathrm{LaB}_{6}$, it is also important to note that there are many more applications for this material beyond building specialized windows for heat control. Many new applications of $\mathrm{LaB}_{6}$ nanoparticles have come to light in recent years. For example, the photothermal conversion properties of $\mathrm{LaB}_{6}$ are being explored for biomedical applications like cancer [75,88-90]. LaB $_{6}$ nanoparticles also interact with bacteria, and studies focusing on ablation and hydrogen production are ongoing [91,92]. Looking beyond nanoparticles to nanowires, $\mathrm{LaB}_{6}$ is now known to be an efficient field emitter [78-80]. There are many more potential applications, and this list offers you a small sampling of how this material is advancing multiple fields of research.

Future Challenges of Plasmonic $\mathrm{LaB}_{6}$

Much has been learned about the optical behavior and tunability of $\mathrm{LaB}_{6}$, and work is ongoing. Perhaps the unspoken secret of this research space is how challenging it is to develop the synthetic procedures to make small phase-pure $\mathrm{LaB}_{6}$ nanoparticles. Ball milling bulk particles to reduce the particle size introduces contaminants and does not maintain uniform morphology. Cutting single crystals into nano-sized particles is difficult and does not translate easily to larger scale [78]; plasma methods do not offer a means of easy control for tuning [93], etc.

To further complicate matters, the mechanism behind the formation of the $\mathrm{B}_{6}$ cluster is still unknown. For decades it was assumed that high temperatures $\left(>1200{ }^{\circ} \mathrm{C}\right)$ and pressures were energetically required to make $\mathrm{LaB}_{6}$, but that is not the case [94,95]. It has also been assumed that a reducing agent such as magnesium was required to drive the reaction $[59,96]$, but new reports find this to be untrue $[74,95]$. Only recently was it found that the halogen of the lanthanum salt influences the reaction to expand or contract the crystal lattice, and can act as a bridging ligand between La atoms in low temperature reactions $[48,58]$.

In order advance this field it is becoming increasingly important to build a better understanding of the chemistry involved in the formation of $\mathrm{LaB}_{6}$. In learning more about the mechanism, it will be much easier to tune these particles for optical applications as well as electronics, thermionics, and solar energy. With a better understanding of the formation of the robust boron clusters in $\mathrm{LaB}_{6}$ and the potential interplay of boron and halogens, we will likely discover new applications previously unexplored.

\section{Conclusions}

$\mathrm{LaB}_{6}$ is an intriguing plasmonic material that has gained much attention in the last decade for its ability to intensely absorb in the NIR region of the electromagnetic spectrum. Large advances have been made in developing methods to finely tune the position of the plasmon, making the shift from the visible region to the NIR possible. This review explains how some of the fundamentals of the $\mathrm{LaB}_{6}$ framework influence the optical properties, and how the plasmon can be tuned by controlling lattice defects, particle size and shape, and through doping. As advances continue to be made in this field, it is hoped that a there will be a better understanding of how the structure forms, enabling better control over this system and potentially opening the door to new applications in need of stable plasmonic nanoparticles. 
Funding: This research received no external funding.

Acknowledgments: This work was supported by the Molecular Foundry at Lawrence Berkeley National Laboratory, a user facility supported by the Office of Science, Office of Basic Energy Sciences, of the U.S. Department of Energy (DOE) under Contract No. DE-AC02-05CH11231.

Conflicts of Interest: The authors declare no conflict of interest.

\section{References}

1. Aslam, U.; Rao, V.G.; Chavez, S.; Linic, S. Catalytic conversion of solar to chemical energy on plasmonic metal nanostructures. Nat. Catal. 2018, 1, 656-665. [CrossRef]

2. Byers, C.P.; Zhang, H.; Swearer, D.F.; Yorulmaz, M.; Hoener, B.S.; Huang, D.; Hoggard, A.; Chang, W.-S.; Mulvaney, P.; Ringe, E.; et al. From tunable core-shell nanoparticles to plasmonic drawbridges: Active control of nanoparticle optical properties. Sci. Adv. 2015, 1, e1500988. [CrossRef] [PubMed]

3. Wen, J.; Wang, W.J.; Li, N.; Li, Z.F.; Lu, W. Plasmonic optical convergence microcavity based on the metal-insulator-metal microstructure. Appl. Phys. Lett. 2017, 110, 231105. [CrossRef]

4. Zhang, J.Z.; Noguez, C. Plasmonic Optical Properties and Applications of Metal Nanostructures. Plasmonics 2008, 3, 127-150. [CrossRef]

5. Takahata, R.; Yamazoe, S.; Koyasu, K.; Tsukuda, T. Surface Plasmon Resonance in Gold Ultrathin Nanorods and Nanowires. J. Am. Chem. Soc. 2014, 136, 8489-8491. [CrossRef] [PubMed]

6. Lee, K.-S.; El-Sayed, M.A. Gold and Silver Nanoparticles in Sensing and Imaging: Sensitivity of Plasmon Response to Size, Shape, and Metal Composition. J. Phys. Chem. B 2006, 110, 19220-19225. [CrossRef] [PubMed]

7. Xiaoa, L.; Sub, Y.; Qiud, W.; Liua, Y.; Rand, J.; Wua, J.; Lua, F.; Shaod, F.; Tangc, D.; Peng, P. Solar radiation shielding properties of transparent LaB6 filters through experimental and first-principles calculation methods. Ceram. Int. 2016, 42, 14278-14281. [CrossRef]

8. Bao, L.; Chao, L.; Wei, W.; Tegus, O. Tunable transmission light in nanocrystalline $\mathrm{La}_{1-x} \mathrm{Eu}_{x} \mathrm{~B}_{6}$. Mater. Lett. 2015, 139, 187-190. [CrossRef]

9. Xiao, L.; Su, Y.; Zhou, X.; Chen, H.; Tan, J.; Hu, T.; Yan, J.; Peng, P. Origins of high visible light transparency and solar heat-shielding performance in LaB6. Appl. Phys. Lett. 2012, 101, 041913. [CrossRef]

10. Mattox, T.M.; Ye, X.; Manthiram, K.; Schuck, P.J.; Alivisatos, A.P.; Urban, J.J. Chemical Control of Plasmons in Metal Chalcogenide and Metal Oxide Nanostructures. Adv. Mater. 2015, 27, 5830-5837. [CrossRef]

11. Lounis, S.D.; Runnerstrom, E.L.; Llordés, A.; Milliron, D.J. Defect Chemistry and Plasmon Physics of Colloidal Metal Oxide Nanocrystals. J. Phys. Chem. Lett. 2014, 5, 1564-1574. [CrossRef] [PubMed]

12. Wolf, A.; Kodanek, T.; Dorfs, D. Tuning the LSPR in copper chalcogenide nanoparticles by cation intercalation, cation exchange and metal growth. Nanoscale 2015, 7, 19519-19527. [CrossRef] [PubMed]

13. Mattox, T.M.; Bergerud, A.; Agrawal, A.; Milliron, D.J. Influence of Shape on the Surface Plasmon Resonance of Tungsten Bronze Nanocrystals. Chem. Mater. 2014, 26, 1779-1784. [CrossRef]

14. Zhao, Y.; Pan, H.; Lou, Y.; Qiu, X.; Zhu, J.; Burda, C. Plasmonic $\mathrm{Cu}_{2-x} \mathrm{~S}$ Nanocrystals: Optical and Structural Properties of Copper-Deficient Copper(I) Sulfides. J. Am. Chem. Soc. 2009, 131, 4253-4261. [CrossRef] [PubMed]

15. González, A.L.; Noguez, C.; Beránek, J.; Barnard, A.S. Size, Shape, Stability, and Color of Plasmonic Silver Nanoparticles. J. Phys. Chem. C 2014, 118, 9128-9136. [CrossRef]

16. Amendola, V.; Pilot, R.; Frasconi, M.; Maragò, O.M.; Iatì, M.A. Surface plasmon resonance in gold nanoparticles: A review. J. Phys. Condens. Matter 2017, 29, 203002. [CrossRef]

17. Liu, P.; Wang, H.; Li, X.; Rui, M.; Zeng, H. Localized surface plasmon resonance of Cu nanoparticles by laser ablation in liquid media. RSC Adv. 2015, 5, 79738-79745. [CrossRef]

18. Duan, H.; Xuan, Y. Synthesis and optical absorption of Ag/CdS core/shell plasmonic nanostructure. Sol. Energy Mater. Sol. Cells 2014, 121, 8-13. [CrossRef]

19. Chen, Y.; Wu, H.; Li, Z.; Wang, P.; Yang, L.; Fang, Y. The Study of Surface Plasmon in Au/Ag Core/Shell Compound Nanoparticles. Plasmonics 2012, 7, 509-513. [CrossRef]

20. Schmidt, P.H.; Joy, D.C.; Longinotti, L.D.; Leamy, H.J.; Ferris, S.D.; Fisk, Z. Anisotropy of thermionic electron emission values for $\mathrm{LaB}_{6}$ single-crystal emitter cathodes. Appl. Phys. Lett. 1976, 29, 400-401. [CrossRef] 
21. Ahmed, H.; Broers, A.N. Lanthanum Hexaboride Electron Emitter. J. Appl. Phys. 1972, 43, $2185-2192$. [CrossRef]

22. Goebel, D.M.; Hirooka, Y.; Sketchley, T.A. Large-area lanthanum hexaboride electron emitter. Rev. Sci. Instrum. 1985, 56, 1717-1722. [CrossRef]

23. Zhang, H.; Tang, J.; Zhang, Q.; Zhao, G.; Yang, G.; Zhang, J.; Zhou, O.; Qin, L.-C. Field emission of electrons from single $\mathrm{LaB}_{6}$ nanowires. Adv. Mater. 2006, 18, 87-91. [CrossRef]

24. Zhou, S.; Zhang, J.; Liu, D.; Lin, Z.; Huang, Q.; Bao, L.; Ma, R.; Wei, Y. Synthesis and properties of nanostructured dense LaB6 cathodes by arc plasma and reactive spark plasma sintering. Acta Mater. 2010, 58, 4978-4985. [CrossRef]

25. Back, T.C.; Schmid, A.K.; Fairchild, S.B.; Boeckl, J.J.; Cahay, M.; Derkink, F.; Chen, G.; Sayir, A. Work function characterization of directionally solidified $\mathrm{LaB}_{6}-\mathrm{VB}_{2}$ eutectic. Ultramicroscopy 2017, 183, 67-71. [CrossRef] [PubMed]

26. Liu, H.; Zhang, X.; Ning, S.; Xiao, Y.; Zhang, J. The electronic structure and work functions of single crystal LaB6 typical crystal surfaces. Vacuum 2017, 143, 245-250. [CrossRef]

27. Ning, S.-Y.; Iitaka, T.; Yang, X.-Y.; Wang, Y.; Zhao, J.-J.; Li, Z.; Zhang, J.-X. Enhanced thermionic emission performance of LaB6 by Ce doping. J. Alloys Compd. 2018, 760, 1-5. [CrossRef]

28. Torgasin, K.; Morita, K.; Zen, H.; Masuda, K.; Katsurayama, T.; Murata, T.; Suphakul, S.; Yamashita, H.; Nogi, T.; Kii, T.; et al. Thermally assisted photoemission effect on $\mathrm{CeB}_{6}$ and $\mathrm{LaB}_{6}$ for application as photocathodes. Phys. Rev. Accel. Beams 2017, 20, 073401. [CrossRef]

29. Voss, J.; Vojvodic, A.; Chou, S.H.; Howe, R.T.; Abild-Pedersen, F. Inherent Enhancement of Electronic Emission from Hexaboride Heterostructure. Phys. Rev. Appl. 2014, 2, 024004. [CrossRef]

30. Schelm, S.; Smith, G.B.; Garrett, P.D.; Fisher, W.K. Tuning the surface-plasmon resonance in nanoparticles for glazing applications. J. Appl. Phys. 2005, 97, 124314. [CrossRef]

31. Schelm, S.; Smith, G.B. Dilute LaB6 nanoparticles in polymer as optimized clear solar control glazing. Appl. Phys. Lett. 2003, 82, 4346-4348. [CrossRef]

32. Bogomol, I.; Nishimura, T.; Nesterenko, Y.; Vasylkiv, O.; Sakka, Y.; Loboda, P. The bending strength temperature dependence of the directionally solidified eutectic $\mathrm{LaB}_{6}-\mathrm{ZrB}_{2}$ composite. J. Alloys Compd. 2011, 509, 6123-6129. [CrossRef]

33. Chen, D.; Min, G.; Wu, Y.; Yu, H.; Zhang, L. The preparation and composition design of boron-rich lanthanum hexaboride target for sputtering. J. Alloys Compd. 2015, 638, 380-386. [CrossRef]

34. Gridneva, I.V.; Lazorenko, V.I.; Lotsko, D.V.; Mil'man, Y.V.; Paderno, Y.B.; Chugunova, S.I. Mechanical properties of single-crystal lanthanum hexaboride with local loading. Sov. Powder Metall. Met. Ceram. 1990, 29, 967-972. [CrossRef]

35. Loboda, P.I.; Kysla, H.P.; Dub, S.M.; Karasevs'ka, O.P. Mechanical properties of the monocrystals of lanthanum hexaboride. Mater. Sci 2009, 45, 108-113. [CrossRef]

36. Mitterer, C.; Komenda-Stallmaier, J.; Losbichler, P.; Schmölz, P.; Störi, H. Decorative boride coatings based on $\mathrm{LaB}_{6}$. Surf. Coat. Technol. 1995, 74-75, 1020-1027. [CrossRef]

37. Bogomol, I.; Nishimura, T.; Vasylkiv, O.; Sakka, Y.; Loboda, P. High-temperature strength of directionally reinforced $\mathrm{LaB}_{6}-\mathrm{TiB}_{2}$ composite. J. Alloys Compd. 2010, 505, 130-134. [CrossRef]

38. Buckingham, J.D. Thermionic emission properties of a lanthanum hexaboride/rhenium cathode. Br. J. Appl. Phys. 1965, 16, 1821. [CrossRef]

39. Xu, G.-L.; Chen, J.-D.; Xia, Y.-Z.; Liu, X.-F.; Liu, Y.-F.; Zhou, X.-Z. First-Principles Calculations of Elastic and Thermal Properties of Lanthanum Hexaboride. Chin. Phys. Lett. 2009, 26, 056201.

40. Hu, P.; Zhang, X.-H.; Han, J.-C.; Luo, X.-G.; Du, S.-Y. Effect of Various Additives on the Oxidation Behavior of $\mathrm{ZrB}_{2}$-Based Ultra-High-Temperature Ceramics at $1800{ }^{\circ} \mathrm{C}$. J. Am. Ceram. Soc. 2010, 93, 345-349. [CrossRef]

41. Kelly, J.P.; Kanakala, R.; Graeve, O.A. A Solvothermal Approach for the Preparation of Nanostructured Carbide and Boride Ultra-High-Temperature Ceramics. J. Am. Ceram. Soc. 2010, 93, 3035-3038. [CrossRef]

42. Marchenko, A.A.; Cherepanov, V.V.; Tarashchenko, D.T.; Kazantseva, Z.I.; Naumovets, A.G. A low work function substrate for STM studies of objects with poor tunneling transparency: Lanthanum hexaboride (100). Surf. Sci. 1998, 416, 460-465. [CrossRef]

43. Monteverde, F.; Alfano, D.; Savino, R. Effects of LaB6 addition on arc-jet convectively heated SiC-containing $\mathrm{ZrB}_{2}$-based ultra-high temperature ceramics in high enthalpy supersonic airflows. Corros. Sci. 2013, 75, 443-453. [CrossRef] 
44. Cortie, M.B.; McDonagh, A.M. Synthesis and Optical Properties of Hybrid and Alloy Plasmonic Nanoparticles. Chem. Rev. 2011, 111, 3713-3735. [CrossRef] [PubMed]

45. Hou, W.; Cronin, S.B. A Review of Surface Plasmon Resonance-Enhanced Photocatalysis. Adv. Funct. Mater. 2013, 23, 1612-1619. [CrossRef]

46. Linic, S.; Christopher, P.; Ingram, D.B. Plasmonic-metal nanostructures for efficient conversion of solar to chemical energy. Nat. Mater. 2011, 10, 911-921. [CrossRef] [PubMed]

47. Lu, X.; Rycenga, M.; Skrabalak, S.E.; Wiley, B.; Xia, Y. Chemical Synthesis of Novel Plasmonic Nanoparticles. Annu. Rev. Phys. Chem. 2009, 60, 167-192. [CrossRef] [PubMed]

48. Mattox, T.M.; Groome, C.; Doran, A.; Beavers, C.M.; Urban, J.J. Chloride influence on the formation of lanthanum hexaboride: An in-situ diffraction study. J. Cryst. Growth 2018, 486, 60-65. [CrossRef]

49. Nagao, T.; Kitamura, K.; Iizuka, Y.; Oshima, C. Surface phonons of $\operatorname{LaB}_{6}(100)$ : Deformation of boron octahedra at the surface. Surf. Sci. 1993, 290, 436-444. [CrossRef]

50. Nagao, T.; Kitamura, T.; Iizuka, T.; Umeuchi, M.; Oshima, C. Deformation of octahedra at LaB 6 (100) surface studied by HREELS. Surf. Sci. 1993, 287-288, 391-395. [CrossRef]

51. Rokuta, E.; Yamamoto, N.; Hasegawa, Y.; Trenary, M.; Nagao, T.; Oshima, C.; Otani, S. Deformation of boron networks at the $\mathrm{LaB}_{6}(111)$ surface. Surf. Sci. 1998, 416, 363-370. [CrossRef]

52. Li, Y.; Cao, Y.; Jia, D. A general strategy for synthesis of metal nanoparticles by a solid-state redox route under ambient conditions. J. Mater. Chem. A 2014, 2, 3761-3765. [CrossRef]

53. Polte, J. Fundamental growth principles of colloidal metal nanoparticles-A new perspective. CrystEngComm 2015, 17, 6809-6830. [CrossRef]

54. Adachi, K.; Miratsu, M.; Asahi, T. Absorption and scattering of near-infrared light by dispersed lanthanum hexaboride nanoparticles for solar control filters. J. Mater. Res. 2010, 25, 510-521. [CrossRef]

55. Sato, Y.; Terauchi, M.; Mukai, M.; Kaneyama, T.; Adachi, K. High energy-resolution electron energy-loss spectroscopy study of the dielectric properties of bulk and nanoparticle $\mathrm{LaB}_{6}$ in the near-infrared region. Ultramicroscopy 2011, 111, 1381-1387. [CrossRef] [PubMed]

56. Zhang, L.; He, W.J.; Tolochko, O.V.; Polzik, L.; Min, G.H. Morphology Characterization and Optical Properties Analysis for Nanostructured Lanthanum Hexaboride Powders. Adv. Mater. Res. 2009, 79-82, 107-110. [CrossRef]

57. Hang, C.-L.; Yang, L.-X.; Wang, F.; Xu, Y.-B.; Yi, C.-Y. Melt-assisted synthesis to lanthanum hexaboride nanoparticles and cubes. Bull. Mater. Sci. 2017, 40, 1241-1245. [CrossRef]

58. Mattox, T.M.; Groome, C.; Doran, A.; Beavers, C.M.; Urban, J.J. Anion-mediated negative thermal expansion in lanthanum hexaboride. Solid State Commun. 2017, 265, 47-51. [CrossRef]

59. Zhang, M.; Yuan, L.; Wang, X.; Fan, H.; Wang, X.; Wu, X.; Wang, H.; Qian, Y. A low-temperature route for the synthesis of nanocrystalline LaB6. J. Solid State Chem. 2008, 181, 294-297. [CrossRef]

60. Yuan, Y.; Zhang, L.; Liang, L.; He, K.; Liu, R.; Min, G. A solid-state reaction route to prepare LaB $_{6}$ nanocrystals in vacuum. Ceram. Int. 2011, 37, 2891-2896. [CrossRef]

61. Brewer, J.R.; Deo, N.; Wang, Y.M.; Cheung, C.L. Lanthanum Hexaboride Nanoobelisks. Chem. Mater. 2007, 19, 6379-6381. [CrossRef]

62. Zhang, H.; Shang, Q.; Tang, J.; Qin, L.-C. Single-crystalline LaB 6 nanowires. J. Am. Chem. Soc. 2005, 127, 2862-2863. [CrossRef] [PubMed]

63. Mattox, T.M.; Chockkalingam, S.; Roh, I.; Urban, J.J. Evolution of Vibrational Properties in Lanthanum Hexaboride Nanocrystals. J. Phys. Chem. C 2016, 120, 5188-5195. [CrossRef]

64. Groome, C.; Roh, I.; Mattox, T.M.; Urban, J.J. Effects of size and structural defects on the vibrational perperties of lanthanum hexaboride nanocrystals. ACS Omega 2017, 2, 2248-2254. [CrossRef]

65. Etourneau, J. Critical survey of rare-earth borides: Occurence, crystal chemistry and physical properties. J. Less-Common Met. 1985, 110, 267-281. [CrossRef]

66. Cahill, J.T.; Alberga, M.; Bahena, J.; Pisano, C.; Borja-Urby, R.; Vasquez, V.R.; Edwards, D.; Misture, S.T.; Graeve, O.A. Phase Stability of Mixed-Cation Alkaline-Earth Hexaborides. Cryst. Growth Des. 2017, 17, 3450-3461. [CrossRef]

67. Kasai, H.; Nishibori, E. Spatial distribution of electrons near the Fermi level in the metallic $\mathrm{LaB}_{6}$ through accurate X-ray charge density study. Sci. Rep. 2017, 7, 41375. [CrossRef]

68. Etourneau, J.; Hagenmuller, P. Structure and physical features of the rare-earth borides. Philos. Mag. B 1985, 52, 589-610. [CrossRef] 
69. Chao, L.; Bao, L.; Wei, W.; Tegus, O. Optical properties of Yb-doped $\mathrm{LaB}_{6}$ from first-principles calculation. Mod. Phys. Lett. B 2016, 30, 1650091. [CrossRef]

70. Chao, L.; Bao, L.; Shi, J.; Wei, W.; Tegus, O.; Zhang, Z. The effect of Sm-doping on optical properties of LaB6 nanoparticles. J. Alloys Compd. 2015, 622 (Suppl. C), 618-621. [CrossRef]

71. Mattox, T.M.; Coffman, D.K.; Roh, I.; Sims, C.; Urban, J.J. Moving the Plasmon of LaB 6 from IR to Near-IR via Eu-Doping. Materials 2018, 11, 226. [CrossRef] [PubMed]

72. Noguez, C. Surface Plasmons on Metal Nanoparticles: The Influence of Shape and Physical Environment. J. Phys. Chem. C 2007, 111, 3806-3819. [CrossRef]

73. Hong, Y.; Zhang, X.; Li, B.; Li, M.; Shi, Q.; Wang, Y.; Li, L. Size dependent optical properties of LaB 6 nanoparticles enhanced by localized surface plasmon resonance. J. Rare Earth 2013, 31, 1096-1101. [CrossRef]

74. Mattox, T.M.; Agrawal, A.; Milliron, D.J. Low Temperature Synthesis and Surface Plasmon Resonance of Colloidal Lanthanum Hexaboride ( $\left.\mathrm{LaB}_{6}\right)$ Nanocrystals. Chem. Mater. 2015, 27, 6620-6624. [CrossRef]

75. Chen, C.-J.; Chen, D.-H. Preparation of $\mathrm{LaB}_{6}$ nanoparticles as a novel and effective near-infrared photothermal conversion material. Chem. Eng. J. 2012, 180, 337-342. [CrossRef]

76. Rivera, V.A.G.; Ferri, A.F.; Marega, E., Jr. Localized Surface Plasmon Resonances: Noble Metal Nanoparticle Interaction with Rare-Earth Ions. In Plasmonics: Principles and Applications; IntechOpen: Rijeka, Croatia, 2012.

77. Kanakala, R.; Rojas-George, G.; Graeve, O.A. Unique Preparation of Hexaboride Nanocubes: A First Example of Boride Formation by Combustion Synthesis. J. Am. Ceram. Soc. 2010, 93, 3136-3141. [CrossRef]

78. Zhang, H.; Tang, J.; Yuan, J.; Ma, J.; Shinya, N.; Nakajima, K.; Murakami, H.; Ohkubo, T.; Qin, L.-C. Nanostructured LaB6 Field Emitter with Lowest Apical Work Function. Nano Lett. 2010, 10, 3539-3544. [CrossRef] [PubMed]

79. Xu, J.; Hou, G.; Li, H.; Zhai, T.; Dong, B.; Yan, H.; Wang, Y.; Yu, B.; Bando, Y.; Golberg, D. Fabrication of vertically aligned single-crystalline lanthanum hexaboride nanowire arrays and investigation of their field emission. NPG Asia Mater. 2013, 5, e53. [CrossRef]

80. Xu, J.Q.; Zhao, Y.M.; Zhang, Q.Y. Enhanced electron field emission from single-crystalline $\mathrm{LaB}_{6}$ nanowires with ambient temperature. J. Appl. Phys. 2008, 104, 124306. [CrossRef]

81. Machida, K.; Adachi, K. Particle shape inhomogeneity and plasmon-band broadening of solar-control LaB 6 nanoparticles. J. Appl. Phys. 2015, 118, 013103. [CrossRef]

82. Chao, L.; Bao, L.; Wei, W.; Tegus, O.; Zhang, Z. Effects of nanoparticle shape and size on optical properties of $\mathrm{LaB}_{6}$. Plasmonics 2016, 11, 697-701. [CrossRef]

83. Kelly, K.L.; Coronado, E.; Zhao, L.L.; Schatz, G.C. The Optical Properties of Metal Nanoparticles: The Influence of Size, Shape, and Dielectric Environment. J. Phys. Chem. B 2003, 107, 668-677. [CrossRef]

84. Jiang, F.; Leong, Y.; Saunders, M.; Martyniuk, M.; Faraone, L.; Keating, A.; Dell, J. Uniform Dispersion of Lanthanum Hexaboride Nanoparticles in a Silica Thin Film: Synthesis and Optical Properties. ACS Appl. Mater. Interfaces 2012, 4, 5833-5838. [CrossRef]

85. Seeboth, A.; Ruhmann, R.; Mühling, O. Thermotropic and Thermochromic Polymer Based Materials for Adaptive Solar Control. Materials 2010, 3, 5143-5168. [CrossRef] [PubMed]

86. Yuan, Y.; Zhang, L.; Hu, L.; Wang, W.; Min, G. Size effect of added LaB6 particles on optical properties of $\mathrm{LaB}_{6} /$ Polymer composites. J. Solid State Chem. 2011, 184, 3364-3367. [CrossRef]

87. Takeda, H.; Kuno, H.; Adachi, K. Solar Control Dispersions and Coatings with Rare-Earth Hexaboride Nanoparticles. J. Am. Ceram. Soc. 2008, 91, 2897-2902. [CrossRef]

88. Lai, B.H.; Chen, D.H. LaB6 nanoparticles with carbon-doped silica coating for fluorescence imaging and near-IR photothermal therapy of cancer cells. Acta Biomater. 2013, 9, 7556-7563. [CrossRef] [PubMed]

89. Chen, M.-C.; Lin, Z.-W.; Ling, M.-H. Near-Infrared Light-Activatable Microneedle System for Treating Superficial Tumors by Combination of Chemotherapy and Photothermal Therapy. ACS Nano 2016, 10, 93-101. [CrossRef] [PubMed]

90. Cheng, F.-Y.; Chen, C.-T.; Yeh, C.-S. Comparative efficiencies of photothermal destruction of malignant cells using antibody-coated silica@Au nanoshells, hollow Au/Ag nanospheres and Au nanorods. Nanotechnology 2009, 20, 425104. [CrossRef]

91. Lai, B.-H.; Chen, D.-H. Vancomycin-modified $\mathrm{LaB}_{6} @ \mathrm{SiO}_{2} / \mathrm{Fe}_{3} \mathrm{O}_{4}$ composite nanoparticles for near-infrared photothermal ablation of bacteria. Acta Biomater. 2013, 9, 7573-7579. [CrossRef] 
92. Li, Y.; Zhong, N.; Liao, Q.; Fu, Q.; Huang, Y.; Zhu, X.; Li, Q. A biomaterial doped with LaB 6 nanoparticles as photothermal media for enhancing biofilm growth and hydrogen production in photosynthetic bacteria. Int. J. Hydrogen Energy 2017, 42, 5794-5803.

93. Szépvölgyi, J.; Mohai, I.; Károly, Z.; Gál, L. Synthesis of nanosized ceramic powders in a radiofrequency thermal plasma reactor. J. Eur. Ceram. Soc. 2008, 28, 895-899. [CrossRef]

94. Selvan, R.K.; Genish, I.; Perelshtein, I.; Calderon Moreno, J.M.; Gedanken, A. Single Step, Low-Temperature Synthesis of Submicron-Sized Rare Earth Hexaborides. J. Phys. Chem. C 2008, 112, 1795-1802. [CrossRef]

95. Yu, Y.; Wang, S.; Li, W.; Chen, Z. Low temperature synthesis of $\mathrm{LaB}_{6}$ nanoparticles by a molten salt route. Powder Technol. 2018, 323, 203-207. [CrossRef]

96. Wang, L.; Xu, L.; Ju, Z.; Qian, Y. A versatile route for the convenient synthesis of rare-earth and alkaline-earth hexaborides at mild temperatures. CrystEngComm 2010, 12, 3923-3928. [CrossRef]

2018 by the authors. Licensee MDPI, Basel, Switzerland. This article is an open access article distributed under the terms and conditions of the Creative Commons Attribution (CC BY) license (http://creativecommons.org/licenses/by/4.0/). 